\title{
ALTI ROTORLU VE SEKIZ ROTORLU INNSANSIZ HAVA ARAÇLARININ FARKLI BOZUCU ETKİ ALTINDA UÇUŞ PERFORMANSLARININ KARŞILAŞTIRILMASI
}

\author{
1Şahin YILDIRIM (D) , ${ }^{2}$ Nihat ÇABUK ${ }^{(D)}$, ${ }^{3}$ Veli BAKIRCIOĞLU \\ ${ }^{1}$ Erciyes Üniversitesi, Mühendislik Fakültesi, Mekatronik Mühendisliği Bölümü, Kayseri, TÜRKIYYE \\ ${ }^{2,3}$ Aksaray Üniversitesi, Teknik Bilimler Meslek Yüksek Okulu, Elektrik ve Enerji Bölümü, Aksaray, TÜRKIYE \\ 1'sahiny@erciyes.edu.tr, 2nihatcabuk@aksaray.edu.tr, ${ }^{3}$ vbakircioglu@aksaray.edu.tr
}

(Geliş/Received: 21.07.2019; Kabul/Accepted in Revised Form: 18.02.2020)

ÖZ: Bu çalışmada, altı rotorlu ve sekiz rotorlu iki tip insansız hava aracın (İHA) bozucu etki altında performanslarının karşılaştırılması için benzetim gerçekleştirilmiştir. Rotor sayısının farklılığının uçuş performansına etkisinin belirlenmesi esasına dayanan bu çalışmada her iki tip araç için aynı kontrolcü kullanılmıştır. Geleneksel kontrol yöntemlerinden olan Oransal-İntegral-Türevsel (PID) kontrol yöntemi kullanılan bu çalışmada kontrol parametreleri gözleme dayalı çalışmayla belirlenmiştir. Takip edilmesi beklenen bir yörünge için oluşan hatalar dikkate alınarak bu iki hava aracının performanslarının karşılaştırması gerçekleştirilmiştir. Karşılaştırma sonuçları sayısal olarak sunulmuştur. Elde edilen sonuçlara göre, sekiz rotorlu hava aracının altı rotorlu olana göre bozucu etki arttıkça daha kararlı bir uçuş sergilediği gözlemlenmiştir.

Anahtar Kelimeler: Çok rotorlu insansız hava aracı, Matematiksel model, Benzetim, Yörünge takibi

\section{Comparison of Flight Performances of Unmanned Air Vehicle with Six Rotors and Eight Rotors Under Different Disturbance Effects}

\begin{abstract}
In this study, six-rotors and eight-rotors unmanned aerial vehicles have been compared under disruptive effect. To determine the effect of the difference of rotor number on the flight performance, the same controller was used in both types of vehicles. Proportional-Integral-Derivative control method, which is one of the traditional control methods, was used and control parameters were determined by observational study. A comparison of these two air vehicles was made by taking into account the errors trajectory tracking for three axes. The comparison results are presented numerically. According to the results, it was observed that the UAV with eight rotors allowed a more stable flight as the disturbance effect increased compared to the UAV with six rotors.
\end{abstract}

Key Words: Multi-rotors unmanned air vehicle, Mathematical model, Simulation, Trajectory tracking

\section{GİRIŞ (INTRODUCTION)}

İnsansız hava araçları (İHA) sabit kanatlı, döner kanatlı olmak üzere kanat iki çeşitte üretilmektedirler. Döner kanatlılardan olan, çok rotorlu (multikopter) olanlar gün geçtikçe kullanım alanı artan dikey olarak kalkış ve iniş yapabilen hava araçlarıdır. Sıradan hava araçları olma yönünde hızla ilerleyen bu araçlar çeşitli özelliklerde tasarlanıp üretilebilmektedirler. Rotor sayısı ve rotorların konumları bu araçların sınıflandırılmasının temelini oluşturmaktadır. Kullanım amacına göre rotor sayıları ve kaldırma kapasiteleri değişiklik gösteren bu araçlar tarımsal ilaçlama ve gözlemleme, askeri bilgi toplama ve güvenlik, kişisel görüntüleme, endüstriyel tesislerin izlenmesi ve eğlence sektörü olarak 


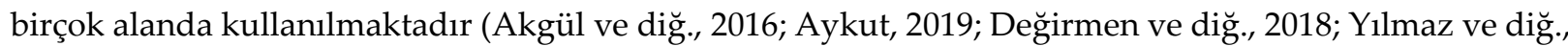
2018).

Multikopterlerin hareketleri motorlara bağlı olan pervanelerin oluşturduğu kaldırma kuvvetleri ile elde edilir. Dönel ve çizgisel olan araç hareketleri motorların dönüş yönleri ve dönme hızları ile ilişkilidir. Karşılıklı yerleştirilen motorların açısal hızları farkı ile oluşan kuvvet farkı aracın hareket yönünü belirlerken farklı yönde dönen motorların dönme hızları farkı da aracın kendi etrafında dönme yönünü belirlemektedir. Motorlar saat yönünde ve saat yönünün tersinde dönmektedir. Her iki dönme yönünde aynı yönde kaldırma kuvveti oluşurken dönme yönünün farklılığı sadece aracın kendi ekseninde dönme hareketini sağlamaktadır. Motorların zıt yönlü bu dönme hareketlerinden olan saat yönünde dönme (CW) ile ifade edilirken saat yönü tersi yönünde dönme (CCW) ile ifade edilmektedir. Multikopterler genellikle dört rotorlu, altı ve sekiz rotorludur. Rotor sayıları artıkça kontrol algoritmalarının karmaşıklığı artsa da özellikle bozucu etkiler altında daha kararlı bir uçuş sergileyebilmektedirler.

Yapılan birçok bilimsel amaçlı deneysel ve benzetim çalışmalarında hem sabit kanatlı hem de döner kanatlı İHA'larla ile ilgili farklı kullanım alanları ilgilidir. Dikey olarak kalkış ve iniş yapabilen İHA'lar özelinde bakıldığında genellikle dört rotorlu, kısmen de altı ve sekiz rotorlu araçlarla ilgili çalışmalar yaygındır (Chamseddine ve diğg., 2014; Eliker ve diğ., 2018; Moussid ve diğ., 2015; Niemiec ve Gandhi, 2017). Moussid ve diğ., bir hekzakopter için birkaç kontrol yönteminin karşılaştırmasını yapmışlardır. Farklı uçuş şartlarında farklı kontrol yöntemlerinin birbirlerine göre üstünlüklerini göstermişlerdir. Niemiec, artı (+) ve çarpı (x) konfigürasyona sahip iki kuadkopterin otonom uçuşta karşılaştırmasını yapmışlardır. Artı konfigürasyonlu aracın kontrolünde ileri-geri ve sağ-sol hareketlerinde çarpı konfigürasyonlu araca göre motorların daha fazla kuvvet üretmek zorunda olduğunu ifade etmişlerdir.

Standart konfigürasyonlardan farklı tasarımlar yapılmıştır (Badr ve diğ., 2019; Lin, 2017; Zabunov ve Mardirossian, 2018). Zabunov, tasarladıkları on iki rotorlu dodekakopter modelinde rotorları düşey eksende ters yerleştirerek rotorlara uygulanan elektriksel güç başına elde edilen kaldırma kuvvetinin incelenmesi esasına dayanan bu çalışmada elde edilen sonuçlara göre rotorların ters yerleştirildiği modelde daha yüksek kütle/güç oranı elde etmişleridir. Badr, yaptıkları tasarım çalışmasında gövdeye atanan koordinat sistemine göre rotorların dönme eksenlerinin değiştirebildiği bir tasarım gerçekleştirmişlerdir. Daha kararlı askıda kalma performansı elde edebilmek için gerçekleştirilen bu tasarımla daha fazla serbestlik derecesi elde edilerek daha kararlı bir uçuş elde ettiklerini ifade etmişlerdir.

Dikey olarak kalkış ve iniş yapan İHÁların kontrolü üzerine yapılan çalışmalarda (Bangura ve Mahony 2017; Brito ve diğ., 2018; Criado ve Rubio, 2015; Muliadi ve Kusumoputro, 2018) Muliadi, dört rotorlu insansız hava aracının yükseklik kontrolünü yapay sinir ağları ve PID ile gerçekleştirerek bunların karşılaştırmasını içeren bir çalışma yapmışlardır. Elde ettikleri sonuçlara göre yapay sinir ağları temelli kontrolcü PID kontrolcüden daha iyi sonuç verdiği görülmüştür. Rotor/motor arızası durumunda çok rotorlu insansız hava araçlarının kontrolü ile ilgili yapılan çalışmalarda (Hu ve diğ., 2016; Mueller ve D'Andrea, 2014; Nguyen ve Hong, 2018) Mueller, rotor/motor arızası durumunda aracın konumunu koruyabilmesi için gerçekleştirdikleri strateji ile aracın konumunu koruyabildiğini göstermişlerdir. Çok rotorlu insansız hava araçlarının olumsuz hava şartlardaki performanslarının incelenmesi ile ilgili yapılan çalı̧̧malarda (Antonelli ve diğ., 2018; López-Estrada ve diğ., 2016; Russell ve diğ., 2016; Solovyev Viktor ve diğ., 2006) Antonelli, aracın ağırlık merkezinin değişmesi ile oluşan olumsuz duruma uygun uyarlamalı bir kontrol yöntemi geliştirip uygulamışlardır.

$\mathrm{Bu}$ çalışmada, İHA'larda rotor sayısının bozucu etki altındaki uçuş performansına etkisi araştırılmıştır. Bu bağlamda, altı ve sekiz rotora sahip iki İHA'nın, farklı bozucu etkiler altında uçuş benzetimleri gerçekleştirilmiş ve sonuçlar karşılaştırılmıştır. Uçuş performansına sadece rotor sayısının etkisinin değerlendirilebilmesi için kontrolcü parametreleri ve rotor başına düşen kütle miktarı sabit tutulmuştur. Kontrolcü olarak literatürde sıklıkla başvurulan ve İHA'ların uçuş kontrolünde etkinliği kanıtlanmış PID kontrolcüler kullanılmıştır. Bu iki aracın uçuş performansının karşılaştırılması, uçuş süresince gerçekleşen konum hatalarının karelerinin ortalamalarının karekökü (RMS) değerleri dikkate alınarak yapılmıştır. Bu çalışma, herhangi bir amaç için kullanılacak bir İHA'nın uçuş performansına etkisi açısından rotor sayısının belirlenmesine katkı sunacağı düşünülmektedir. 
Çalışmanın sunumu, benzetim çalışmaları için gerekli sistemin matematiksel modeli elde edilmesi, farklı bozucu girişler için her iki sistem için uçuş benzetimlerinin gerçekleştirilmesi ile sonuçların karşılaştırılması ve son olarak elde edilen bulguların tartışılması şeklindedir.

\section{SİSTEM TANIMI ve MODELLENMESİ (SYSTEM DESCRIPTION and MODELLING)}

Mekanik sistemlerin matematiksel olarak modellenmesinde karmaşıklığ1 ya da çözümsüzlüğü ortadan kaldırmak için bazı kabuller yapılmaktadır. Bu çalışma için de yapılan kabuller aşağıda verilmiştir.

- Araçların mekanik bileşenleri esnek değildir.

- Araçlar geometrik olarak simetriktir.

- Coğrafi koşullar dikkate alınmamıştır.

- Araçların ağırlık merkezi geometrik merkezlerindedir.

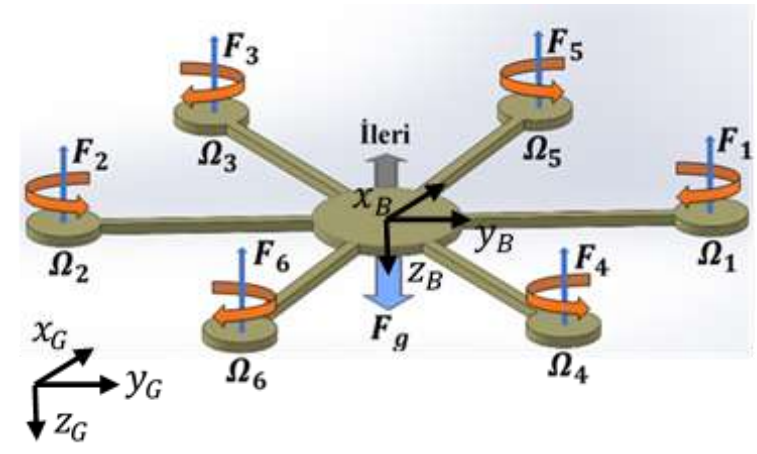

(a)

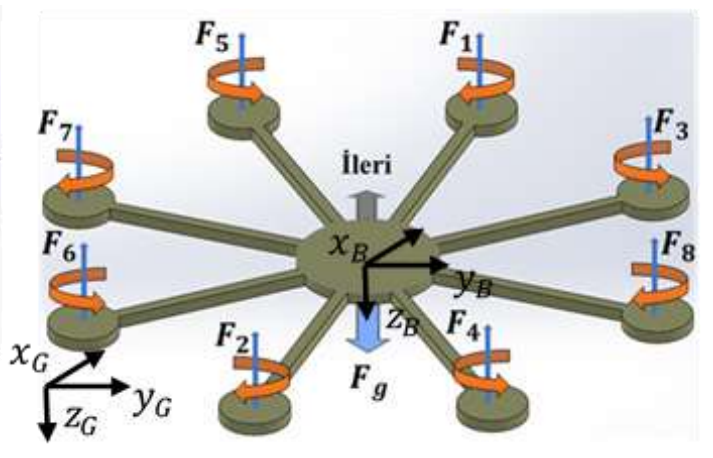

(b)

Şekil 1. Araçlara ait katı model ve serbest cisim diyagramları a) Altı rotorlu, b) Sekiz rotorlu Figure 1. Solid model and free body diagrams of vehicles a) Six rotors, b) Eight rotors

$\mathrm{Bu}$ kabuller çerçevesinde araçların modellenmesinde araca etki eden yerçekimi ivmesi, araçların kütlesi, pervanelerin geometrisine ve açısal hızına bağlı oluşan kaldırma kuvveti, bu kuvvetle oluşan aracın açısal ve çizgisel hızları, rotorların ve pervanelerin ataletleri ve açısal hızlarından kaynaklanan ters moment ve jiroskobik etkiler dikkate alınmıştır.

Çizelge 1. İHAlara ait fiziksel özellikler

Table 1. The physical specifications of the UAVS

\begin{tabular}{c|cccccc}
\hline \hline Değişkenler & $l[\mathrm{~mm}]$ & $F_{\text {rotor }}[\mathrm{N}]$ & $R_{\text {pervane }}[\mathrm{inch}]$ & \multicolumn{2}{c}{ Kütle $[\mathrm{kg}]$} \\
\hline Değerler & 600 & 50 & 15 & 6 rotorlu & 8 rotorlu \\
\hline \hline
\end{tabular}

Sisteme ait fiziksel özellikler Çizelge 1 'de verilmiştir. Motor sayısı $n$ olmak üzere $(i=1 \ldots n)$ her bir motorun $\Omega_{i}$ açısal hızı ile dönmesiyle oluşan kaldırma kuvvetleri $F_{i}$, yerçekimi ve aracın toplam kütlesi ile oluşan yere doğru olan kuvvet $F_{g}$, Şekil 1'de araçların katı modelleri üzerinde vektörel olarak gösterilmiştir.

Bir motora bağlı pervanenin oluşturacağı kaldırma kuvveti motorun açısal hızının karesi ile doğru orantılıdır. Pervanenin mekanik özelliklerine bağlı olarak deneysel bir şekilde elde edilen kuvvet sabiti olan $k_{f}$ ve bu kuvvet arasındaki ilişki Eşitlik 1'de verilmiştir.

$$
F_{i}=k_{f} * \Omega_{i}^{2}
$$

Pervaneler tarafından üretilen toplam kaldırma kuvveti $F_{t}$ Eşitlik 2' deki gibi hesaplanır. 


$$
\mathrm{F}_{\mathrm{t}}=\sum_{\mathrm{i}=1}^{\mathrm{n}} \mathrm{F}_{\mathrm{i}}
$$

Şekil 1'de araç gövdesine sabitlenen gövde koordinat sistemi ve yerde bulunan koordinat sistemleri görülmektedir. Bu iki koordinat sistemi arasındaki ilişki bir matris ile ifade edilebilir. Eşitlik 3'te verilen üç eksene ait dönme matrislerinde $\psi, \theta$ ve $\varphi$ iki koordinat sisteminin eksenleri arasında sırasıyla $x, y, z$ eksenerinde dönme açıları olup bu matrisler ileri yönlü çarpıldığında Eşitlik 4'te görüldüğü gibi iki koordinat sistemi arasındaki dönme matrisi elde edilir.

$$
\begin{aligned}
& \mathrm{R}_{\mathrm{x}}=\left[\begin{array}{ccc}
1 & 0 & 0 \\
0 & \mathrm{c}(\psi) & \mathrm{s}(\psi) \\
0 & -\mathrm{s}(\psi) & \mathrm{c}(\psi)
\end{array}\right], \mathrm{R}_{\mathrm{y}}=\left[\begin{array}{ccc}
\mathrm{c}(\theta) & 0 & -\mathrm{s}(\theta) \\
0 & 1 & 0 \\
\mathrm{~s}(\theta) & 0 & \mathrm{c}(\theta)
\end{array}\right], \mathrm{R}_{\mathrm{z}}=\left[\begin{array}{ccc}
\mathrm{c}(\varphi) & \mathrm{s}(\varphi) & 0 \\
-\mathrm{s}(\varphi) & \mathrm{c}(\varphi) & 0 \\
0 & 0 & 1
\end{array}\right] \\
& { }^{\mathrm{B}} \mathrm{R}_{\mathrm{G}}=\mathrm{R}_{\mathrm{x}} * \mathrm{R}_{\mathrm{y}} * \mathrm{R}_{\mathrm{z}}
\end{aligned}
$$

Elde edilen dönme matrisi de dikkate alınarak aracın gövdesine etki eden net kuvvet Eşitlik 5'te görüldüğü gibi elde edilir. Bu eşitlikte $\mathrm{F}_{d}$ ise aracın gövdesinde hava sürtünmesinden dolayı oluşan sürüklenme kuvveti olup kontrolcünün karmaşıklığının azaltılması amacıyla bu çalışmada sıfır olarak kabul edilmiştir.

$$
\mathrm{F}_{\mathrm{b}}=\mathrm{F}_{\mathrm{t}}-\left({ }^{\mathrm{B}} \mathrm{R}_{\mathrm{G}} * \mathrm{~F}_{\mathrm{g}}+\mathrm{F}_{\mathrm{d}}\right)
$$

Araca etki eden bu kuvvetler araçta bir moment etkisi oluşturabilmektedirler. $\mathrm{Bu}$ momentler pervanelerin ürettiği kuvvet farkından dolayı oluşan, roll-pitch olarak ifade edilen, sırasıyla $x$ ve $y$ eksenlerindeki momentler olup $z$ ekseninde dönmeye neden olan moment ise yaw olarak ifade edilen, rotorlar ile pervanelerin mekanik özelliklerine bağımlı olan ve rotorların dönme yönünü tersinde oluşan tepki momentidir. Bu momentte yine rotorların açısal hızının karesi ile orantılı olup bu oran bir moment sabiti olan $k_{m}$ ile ifade edilir. Bu sabit de kuvvet sabiti gibi deneysel olarak hesaplanır. Moment, rotorun açısal hızı ve moment sabiti arasındaki ilişki aşağıda verilen eşitlikle gösterilir.

$$
\mathrm{M}_{\mathrm{i}}=\mathrm{k}_{\mathrm{m}} * \Omega_{\mathrm{i}}^{2}
$$

Tüm bu momentlerin hesaplanmasında pervanelerin ürettikleri kaldırma kuvvetlerinin moment etkisinin aracın geometrisi ile ilgili olduğu için pervanelerin araç gövdesindeki koordinat eksenine göre yerleşimine göre hesaplanabilir. Bu momentler, momentlere sebep olan kuvvetler ve kuvvetlere sebep olan motorların açısal hızları arasındaki ilişki Eşitlik 7'deki matris eşitliği ile kurulur.

$$
\mathrm{U}=\left[\begin{array}{c}
\mathrm{F}_{\mathrm{t}} \\
\mathrm{M}_{\mathrm{r}} \\
\mathrm{M}_{\mathrm{p}} \\
\mathrm{M}_{\mathrm{y}}
\end{array}\right]=\mathrm{K}_{4 \mathrm{xn}} *\left[\begin{array}{c}
\Omega_{1}{ }^{2} \\
\vdots \\
\Omega_{\mathrm{n}}{ }^{2}
\end{array}\right]
$$

Burada $n$, motor sayısı olmak üzere Eşitlik 8 ve $9^{\prime}$ da verilen $4 x n$ boyutlu $K$ matrisi araçların geometrisine göre oluşturulur. Bu matrisler elde edilirken hesaba katılması gereken diğer bir husus da aracın hareket yönünün kabulüdür. Literatürde hareket yönünün kabulü çarpı (x) konfigürasyon ve artı $(+)$ konfigürasyon olmak üzere iki şekilde yapılmaktadır. Çarpı $(x)$ konfigürasyonda aracın ileri yönü herhangi iki kol ortasından geçen eksene çakışık iken, artı (+) konfigürasyonda aracın ileri yönü herhangi bir kol eksenini ile çakışık olmaktadır. Bu çalışmada her iki araç içinde $x$ konfigürasyon kullanılmış olup bahsi geçen matris bu durum dikkate alınarak oluşturulmuştur. Bunun yanında her iki araçta da düzgün çokgen geometrisine göre motorlar yerleştirilmiş olduğundan Şekil 2'de görüldüğü üzere altı rotorlu araçta iki komşu kol arasındaki açı 60 derece iken sekiz rotorlu olan araçta bu açı 45 derecedir. 


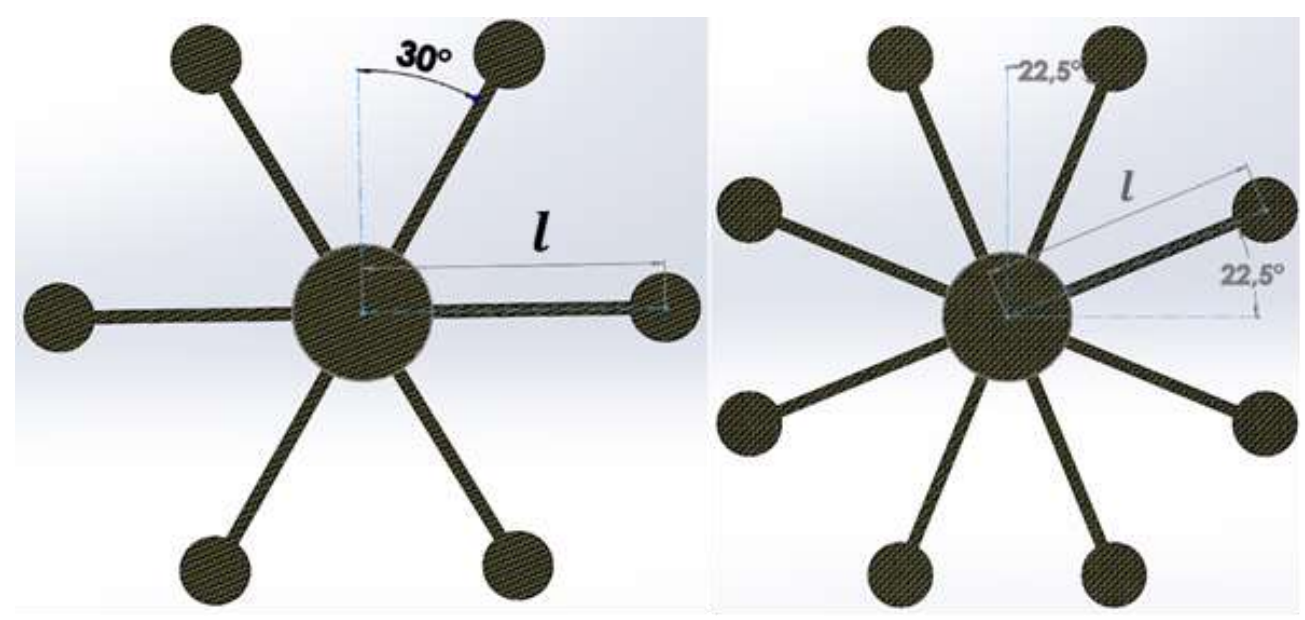

(a)

(b)

Şekil 2. Araçlara ait rotorların yerleşim şekilleri a) Altı rotorlu b) Sekiz rotorlu

Figure 2. Placement of vehicles rotors a) Six rotors b) Eight rotors

$$
\boldsymbol{K}_{4 x \mathbf{6}}=\left[\begin{array}{cccccc}
k_{f} & k_{f} & k_{f} & k_{f} & k_{f} & k_{f} \\
\mathrm{~B} & -\mathrm{B} & -\mathrm{B} * \mathrm{~s}(\alpha) & \mathrm{B} * \mathrm{~s}(\alpha) & \mathrm{B} * \mathrm{~s}(\alpha) & -\mathrm{B} * \mathrm{~s}(\alpha) \\
0 & 0 & \mathrm{~B} * \mathrm{c}(\alpha) & -\mathrm{B} * \mathrm{c}(\alpha) & \mathrm{B} * \mathrm{c}(\alpha) & -\mathrm{B} * \mathrm{c}(\alpha) \\
k_{m} & -k_{m} & k_{m} & -k_{m} & -k_{m} & k_{m}
\end{array}\right]
$$

Sekiz rotorlu araç için de benzer şekilde $K$ matrisi oluşturulur. Burada da matrisin daha sade yazılabilmesi için $A=k_{f} * l, \mathrm{~s}(\beta)=\sin (\beta)$ ve $\mathrm{c}(\beta)=\cos (\beta)$ kısaltmaları yapılmıştır.

$$
\boldsymbol{K}_{4 x \boldsymbol{8}}=\left[\begin{array}{cccccccc}
k_{f} & k_{f} & k_{f} & k_{f} & k_{f} & k_{f} & k_{f} & k_{f} \\
\mathrm{~A} * \mathrm{~s}(\beta) & -\mathrm{A} * \mathrm{~s}(\beta) & \mathrm{A} * \mathrm{c}(\beta) & \mathrm{A} * \mathrm{~s}(\beta) & -\mathrm{A} * \mathrm{~s}(\beta) & -\mathrm{A} * \mathrm{c}(\beta) & -\mathrm{A} * \mathrm{c}(\beta) & \mathrm{A} * \mathrm{c}(\beta) \\
\mathrm{A} * \mathrm{c}(\beta) & -\mathrm{A} * \mathrm{c}(\beta) & \mathrm{A} * \mathrm{~s}(\beta) & -\mathrm{A} * \mathrm{c}(\beta) & \mathrm{A} * \mathrm{c}(\beta) & -\mathrm{A} * \mathrm{~s}(\beta) & \mathrm{A} * \mathrm{~s}(\beta) & -\mathrm{A} * \mathrm{~s}(\beta) \\
k_{m} & k_{m} & -k_{m} & -k_{m} & -k_{m} & -k_{m} & k_{m} & k_{m}
\end{array}\right]
$$

Hem altı hem de sekiz rotorlu araç için $K$ matrisi oluşturulurken aracın gövdesine atanan koordinat sisteminin $x$ ekseninin doğrultusu araçların ileri yönü olarak kabul edilir. Bu eksen iki kolun ortasından geçtiğinden kolların eksenlere yaptığı açlar altı rotorlu için 30 derece $\left(\alpha=30^{\circ}\right)$, sekiz rotorlu için 22,5 derece $\left(\beta=22.5^{\circ}\right.$ ) olarak alınır. Altı rotorlu araçta her bir rotorun açısal hızına göre oluşturulan toplam kuvvet ve momentler arasındaki ilişkiyi kuran matrisin daha sade yazılabilmesi için $B=k_{f} * l, \mathrm{~s}(\alpha)=$ $\sin (\alpha)$ ve $\mathrm{c}(\alpha)=\cos (\alpha)$ kısaltmaları yapılmıştır. Burada $l$ ise bir rotorun dönme ekseni ile aracın geometrik merkezinden geçen eksene olan dik uzaklığı yani kol uzunluğudur.

Eşitlik 7'de verilen genel eşitlik göz önüne alındığında istenilen kuvvet ve moment değerleri için gerekli rotor hızlarının bulunabilmesi için K matrisinin tersi alınması gerekmektedir. Dört rotordan fazla rotorlu araçlarda bu matris kare matris olamayacağından bu matrisin tersinin alınması da standart dışı bir yöntem olan, literatürde pseudo-invers yöntemi olarak bilinen yöntemle alınabilmektedir. Bu yöntemle elde edilen matris ideal bir ters matris olmasa da çok yaklaşık bir sonuç vermektedir [23]. $\boldsymbol{K}$ matrisinin tersi ${ }^{*} \boldsymbol{K}=\boldsymbol{K}^{T} *\left(\boldsymbol{K} * \boldsymbol{K}^{T}\right)^{-1}$ ve $\boldsymbol{U}$ kuvvet ve moment vektörü olmak üzere rotor açısal hızları Eşitlik $10^{\prime}$ da verilmiştir.

$$
\boldsymbol{\Omega}^{2}={ }^{*} \boldsymbol{K} * \boldsymbol{U}
$$

Diğer bir moment ise jiroskobik moment olup bu da yine pervane ile rotorların mekanik özeliğine bağlı olarak rotorların dönme eksenlerindeki bir değişimin neden olduğu momenttir. Jiroskobik momentlerin $z$ ekseninde moment etkisi yok denecek kadar az olduğundan dikkate alınmamıştır. Eşitlik 11 ve $12^{\prime}$ de jiroskobik etkinin $x$ ve y eksenlerine yani roll ve pitch momentlerine etkisi verilmiştir. Bu 
eşitliklerde $I_{z z}$, rotorun dönme eksenindeki ataleti, $p$ ve $q$ ise gövde koordinat sistemine göre sırasıyla pitch ve roll açısal hızlarıdır.

$$
\begin{aligned}
& \mathrm{M}_{x}=-\sum_{i=1}^{\mathrm{n}}(-1)^{i} *\left(I_{z z} * p * \Omega_{i}\right) \\
& \mathrm{M}_{y}=\sum_{i=1}^{\mathrm{n}}(-1)^{i} *\left(I_{z z} * q * \Omega_{i}\right)
\end{aligned}
$$

Araca etki eden toplam moment Eşitlik $13^{\prime}$ te verildiği üzere pervanelerin ürettiği kaldırma kuvvetinden dolayı oluşan roll-pitch-yaw $\left(\mathbf{M}_{r p y}\right)$ momentleri ve jiroskobik etkiden dolayı oluşan momentlerin $\left(\mathbf{M}_{j r}\right)$ toplamı ile elde edilir.

$$
\mathrm{M}_{T}=\mathrm{M}_{r p y}+\mathrm{M}_{j r}=\left[\begin{array}{c}
\mathrm{M}_{r} \\
\mathrm{M}_{p} \\
\mathrm{M}_{y}
\end{array}\right]+\left[\begin{array}{c}
\mathrm{M}_{x} \\
\mathrm{M}_{y} \\
0
\end{array}\right]
$$

Yörünge takibi ve sistem yöneliminin kontrolü için hiyerarşik PID kontrolcüler kullanılmıştır. Kontrolcü mimarisinin şematik gösterimi Şekil 3'te verilmiştir. Sistemin $X$ ve Y yönündeki konumları sırasıyla aracın Roll ve Pitch açıları ile kontrol edilmektedir. $Z$ yönündeki konum ise motorların ürettiği toplam kaldırma kuvveti ile kontrol edilmektedir. $X$ ve $Y$ yönündeki hatalar Eşitlik 14 'teki dönüşüm formülü kullanılarak istenen konumların sağlanması için gerekli Roll ve Pitch açları elde edilmektedir. Şekil 3'te görüldüğü gibi iç kontrol çevriminde hızın, dış kontrol çevriminde konumun kontrol edildiği kaskat kontrolcü yapısı kullanılmıştır.

$\mathrm{Bu}$ bölümde elde edilen sisteme ait matematiksel model kullanılarak benzetim çalışmaları Matlab/Simulink ortamında gerçekleştirilmiştir. Kontrolcü sistemi yine Matlab/Simulink ortamında modellenmiş ve kazançlar deneme-yanılma yoluyla belirlenmiştir.

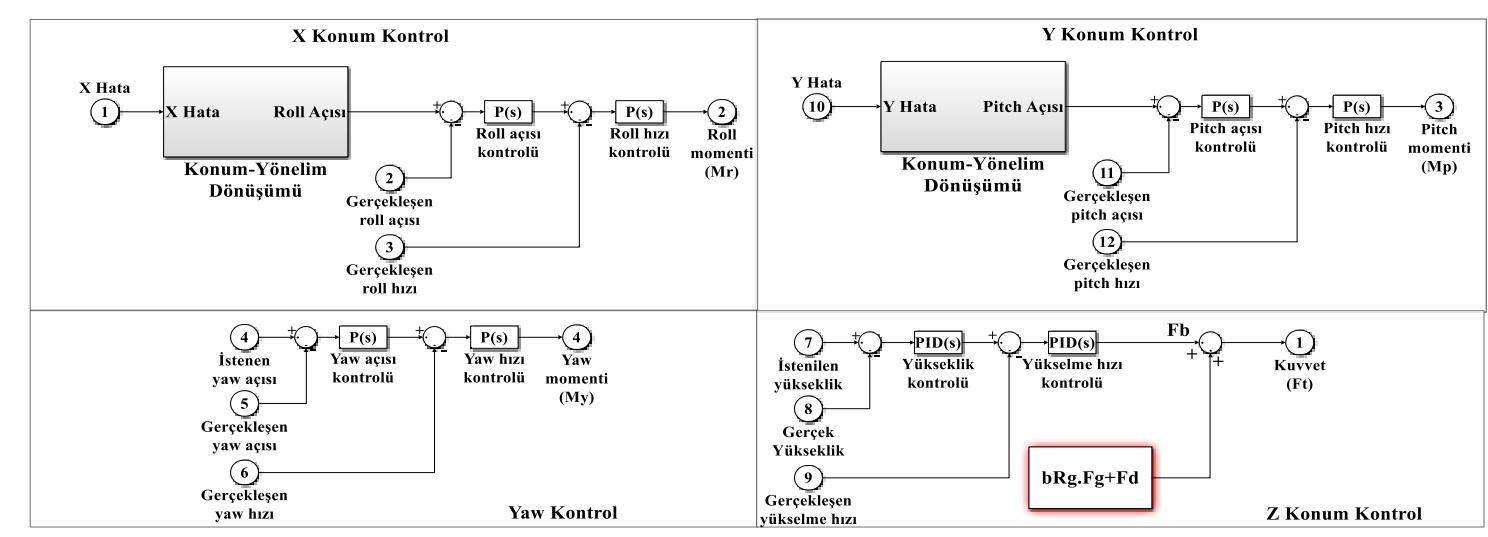

Şekil 3. Benzetim çalışmasında kullanılan kontrolcü mimarisi

Figure 3. Controller architecture used in the simulations

\section{BENZETIM VE SONUÇLAR (SIMULATIONS and RESULTS)}

Modellemesi yapılan sistemlerin benzetiminde PID kontrol yöntemi kullanılmıştır. Hem altı rotorlu hem de sekiz rotorlu araç modelinde aynı kontrolcü kullanılarak aynı bozucu etki altında benzetimler gerçekleştirilmiştir. Şekil 4'te benzetim çalışmasında kullanılan model görülmektedir. Periyodik bir sinyal araçların kütle merkezine üç eksende de bozucu etki olarak uygulanmıştır. Benzetim çalışmaları hem 20 m'de askıda kalma hem de Şekil 5'te gösterilen yörüngenin takibi olmak üzere iki farklı şekilde 30 saniye uçuş süresi için gerçekleştirilmiştir. 


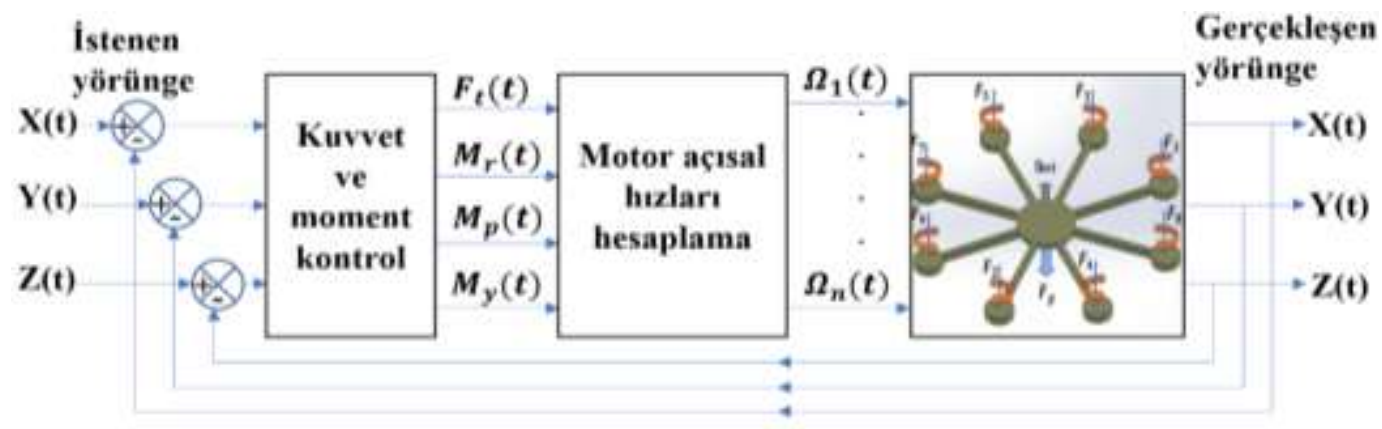

Şekil 4. Benzetim çalışmasında kullanılan sistemin modeli

Figure 4. Model of the system used in the simulation
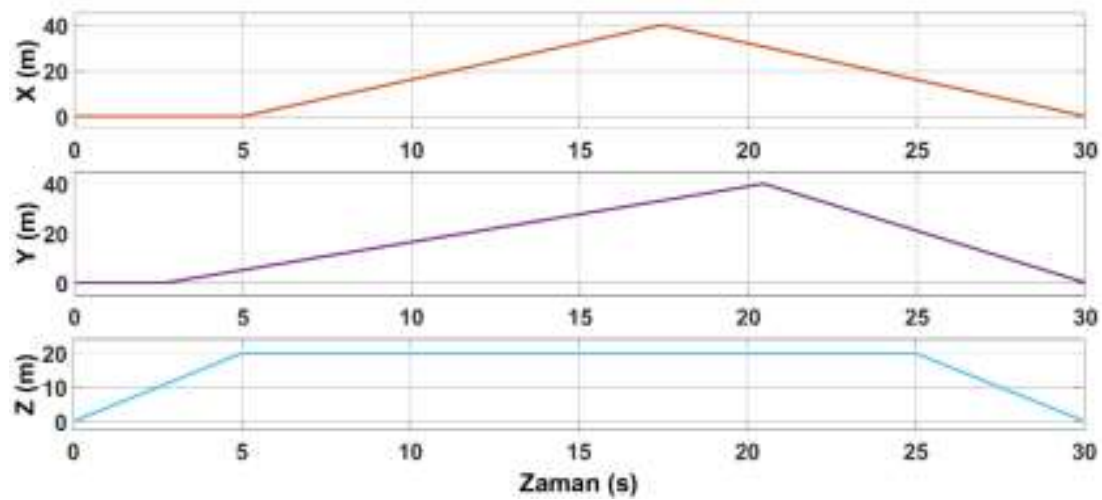

Şekil 5. Benzetim çalışmasında kullanılan yörünge

Figure 5. The trajectory used in the simulations
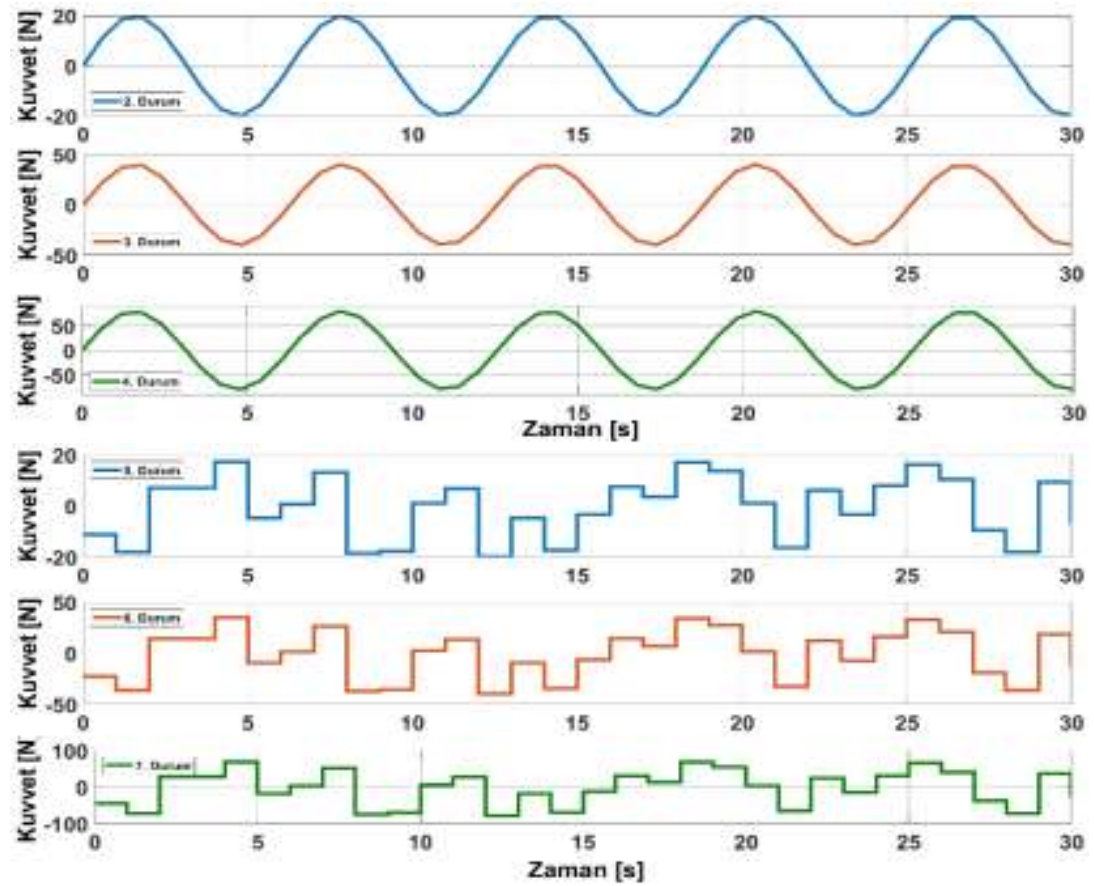

Şekil 6. Benzetimlerde İHA'lara uygulanan bozucu etkiler.

Figure 6. Disturbance effects applied to UAVs in simulations

Benzetim çalışmaları, 3 adedi periyodik ve 3 adedi rastgele olmak üzere 6 farklı tipte bozucu etkinin olduğu durum ve bozucu etkinin olmadığ 1 durum olmak üzere toplamda 7 farklı durum için 
gerçekleştirilmiştir. Bozucu etkiler araç kütle merkezine, her üç eksende de aynı olacak şekilde uygulanmıştır. Çizelge 2'de benzetim çalışmasında kullanılan 7 farklı durum özetlenmiştir. Uygulanan bozucu girişlere ait grafikler Şekil 6'da verilmiştir.

Çizelge 2. Benzetimlerde araçlara uygulanan bozucu etkiler. Table 2. Disturbance effects applied to vehicles in simulations

\begin{tabular}{|c|c|c|c|c|c|c|}
\hline \multicolumn{7}{|c|}{ Bozucu etki [N] } \\
\hline Yok & Periy & odik Giriş G & enliği & Rastgele & Giriş Genli & < Aralığ1 \\
\hline 1. Durum & 2. Durum & 3. Durum & 4. Durum & 5. Durum & 6. Durum & 7. Durum \\
\hline 0 & 20 & 40 & 80 & $\mp 20$ & $\mp 40$ & $\mp 80$ \\
\hline
\end{tabular}

Her iki İHA'nın uçuş benzetiminde, uygulanan bozucu etkiler sonucunda oluşan konum hatalarının RMS değerleri ve bu değerlerin üç eksendeki aritmetik ortalama değerleri Çizelge 3 ve Çizelge 4 'te verilmiştir. Yörünge takibi sırasında oluşan konum hatalarının RMS değerleri uçuş süresince 0.01sn örnekleme zamanı ile hesaplanmıştır.

Çizelge 3.20 m'de 30 s boyunca askıda kalma durumunda oluşan konum hatalarının RMS değerleri Table 3. RMS values of position errors that occur in the case of hovering at $20 \mathrm{~m}$ during $30 \mathrm{~s}$

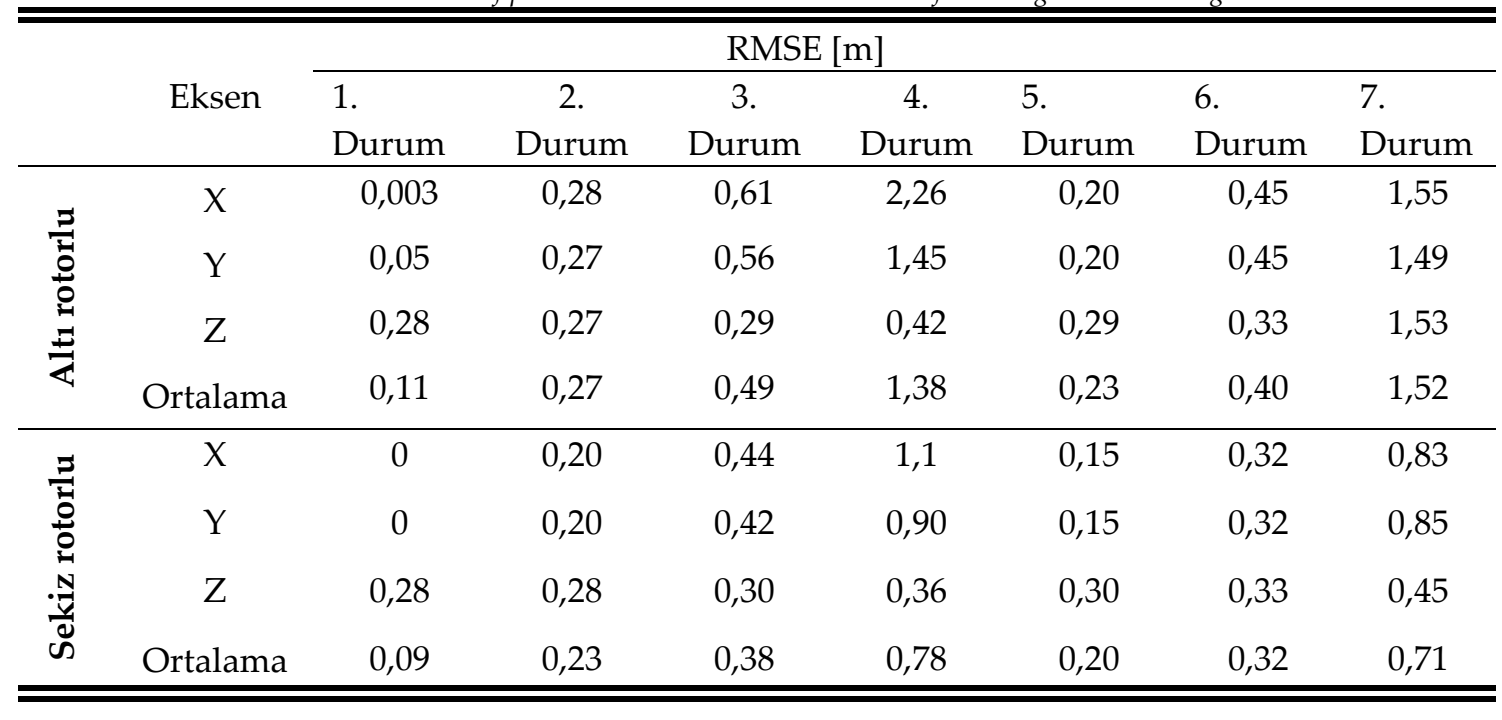


Çizelge 4. Yörünge takibinde oluşan konum hatalarının RMS değerleri Table 4. RMS values of position errors in trajectory tracking

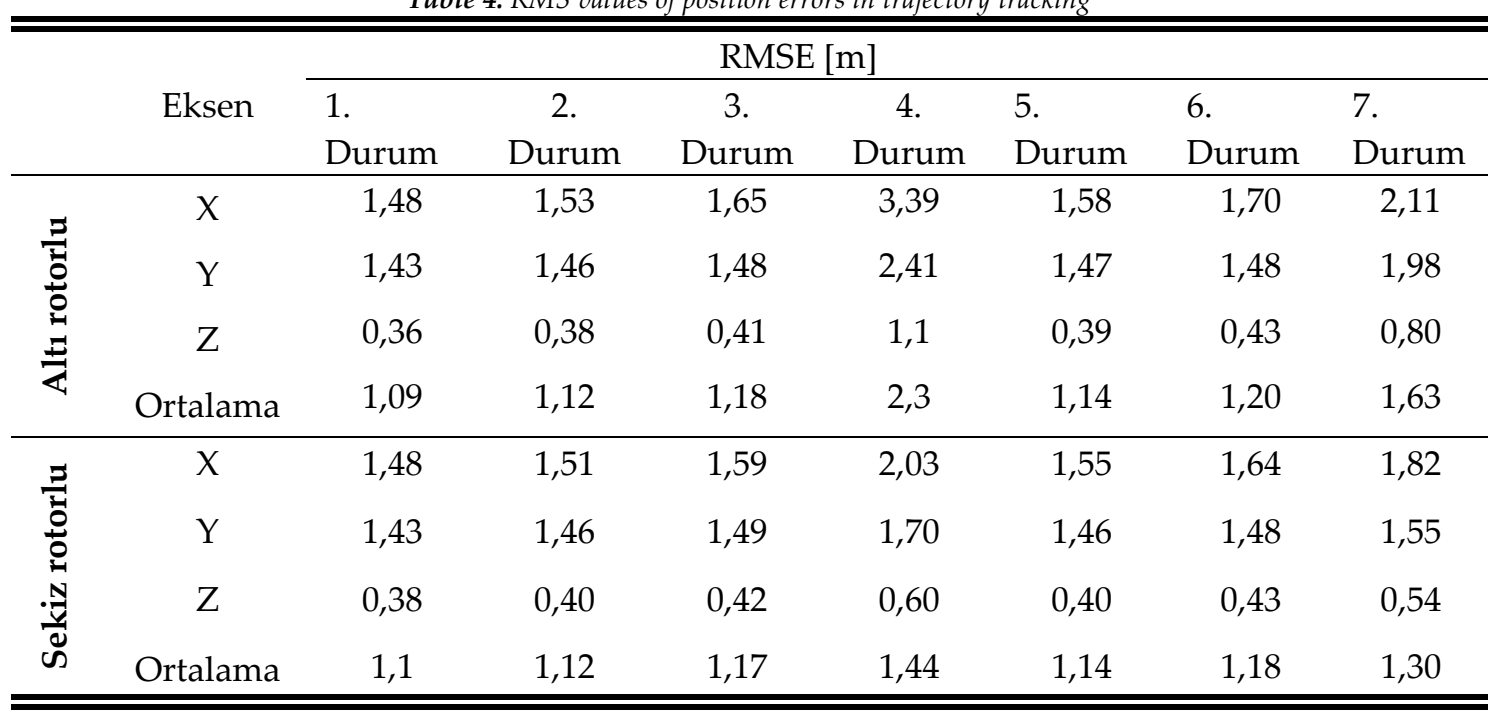

\section{TARTIŞMA (DISCUSSION)}

Altı rotorlu ve sekiz rotorlu dikey olarak iniş-kalkış yapabilen çok rotorlu insansız hava araçlarının modellemesi ve benzetimi yapılan bu çalışmada bu iki tip aracın farklı bozucu etkiler altında performanslarının karşılaştırılması yapılmıştır. PID kontrolcü kullanılan benzetim çalışmasında hem görsel hem de sayısal sonuçlar elde edilmiştir. Askıda kalma ve yörünge takibi olarak iki farklı uçuş tipinde benzetim yapılmış olup her iki benzetim için araçların konum hataları dikkate alınarak karşılaştırma yapılmıştır. Hata kıyaslamada sıklıkla kullanılan, hataların karelerinin ortalamasının karekökü (RMSE) yöntemi kullanılmış olup elde edilen RMSE değerleri Çizelge 3 ve Çizelge 4'te verilmiştir.

Sonuçlar incelendiğinde, beklendiği gibi yörünge takibinde oluşan konum hataları ile askıda kalma durumundaki konum hataları aynı bozucu etki seviyesinde karşılaştırıldığında askıda kalma durumunda oluşan hata diğerine göre daha az olduğu gözlemlenmiştir. Ayrıca, bozucu etkinin genliği arttıkça sekiz rotorlu aracın altı rotorlu araca göre daha az hata ile yörüngeyi takip ettiği gözlemlenmiştir. Bu durum, genliklerin artırılması ile yörünge izleme hatalarındaki artışlar incelendiğine daha net görülmektedir. Bu bağlamda, yörünge izlemede oluşan ortalama RMSE değerinin artış oranı 2. ve 3. Durumlar için kıyaslandığında 6 rotorlu İHA'da \%5,3 bir artış gerçekleşirken 8 rotorlu İHA'da \%4,4 olarak gerçekleşmiştir. Aynı şekilde 3. ve 4. Durumda ortalama RMSE değerinin artış oranı kıyaslandığında 6 rotorlu İHA'da \%95 bir artış gerçekleşirken 8 rotorlu İHA'da \%23 olarak gerçekleşmiştir. Benzer kıyaslama, 5., 6. ve 7. Durumlar içinde yapıldığında 6 rotorlu İHA'da sırasıyla \%5,2 ve\%36 olarak gerçekleşirken, 8 rotorlu İHA'da sırasıyla \%3,5 ve\%10 olarak gerçekleşmiştir. 4. ve 7 . Durumlar için ortalama RMSE değerindeki ani artışların nedeni, periyodik ve rastgele bozucu etki tipinden ve rotor sayısından bağımsız, bozucu etki genliğinin motorların ürettiği toplam kuvvete oranı arttıkça yörünge izleme hatasındaki artış oranı da artmaktadır şeklinde yorumlanabilir. Sonuç olarak, herhangi bir amaç için tasarlanacak olan bir İHA'da rotor sayısının artırılması ile daha iyi bir uçuş performansı elde edilebileceği söylenebilir.

\section{TEŞEKKÜR (ACKNOWLEDGMENT)}

Bu çalışma FBA-2017-7393 kodlu proje kapsamında Erciyes Üniversitesi Bilimsel Araştırma Projeleri Birimi tarafından desteklenmiştir. 


\section{KAYNAKLAR (REFERENCES)}

Akgül, M., Yurtseven, H., Demir, M., Akay, A. E., Gülci, S., \& Öztürk, T., 2016, “İnsansız Hava Araçları ile Yüksek Hassasiyette Sayısal Yükseklik Modeli Üretimi Ve Ormancılıkta Kullanım Olanakları", İstanbul Üniversitesi Orman Fakültesi Dergisi, 66(1), ss.104-118.

Antonelli, G., Cataldi, E., Arrichiello, F., Robuffo Giordano, P., Chiaverini, S., \& Franchi, A., 2018, "Adaptive Trajectory Tracking for Quadrotor MAVs in Presence of Parameter Uncertainties and External Disturbances", IEEE Transactions on Control Systems Technology, 26(1), ss. 248-254.

Aykut, N. O., 2019, “İnsansız Hava Araçlarının Kıyı Çizgisinin Belirlenmesinde Kullanılabilirliğinin Araştırılması", Geomatik, 4(2), ss. 141-146.

Badr, S., Mehrez, O., \& Kabeel, A. E., 2019, “A design modification for a quadrotor UAV: modeling, control and implementation". Advanced Robotics, 33(1), ss. 13-32.

Bangura, M., \& Mahony, R., 2017, “Thrust Control for Multirotor Aerial Vehicles”, IEEE Transactions on Robotics, 33(2), ss. 390-405.

Brito, V., Brito, A., Palma, L. B., \& Gil, P., 2018, "Quadcopter Control Approaches and Performance Analysis", In Proceedings of the 15th International Conference on Informatics in Control, Automation and Robotics (Vol. 1, pp. 86-93). SCITEPRESS - Science and Technology Publications.

Chamseddine, A., Theilliol, D., Sadeghzadeh, I., Zhang, Y., \& Weber, P., 2014, “Optimal reliability design for over-actuated systems based on the MIT rule: Application to an octocopter helicopter testbed", Reliability Engineering and System Safety, 132, ss. 196-206.

Criado, R. M., \& Rubio, F. R., 2015, "Autonomous path tracking control design for a comercial quadcopter", IFAC-PapersOnLine, 28(9), ss. 73-78.

Değirmen, S., Çavdur, F., \& Sebatlı, A., 2018, “Afet OperasyonlarYönetïmïndeInsansiz Hava Araçlarinin Kullanimi: Gözetleme OperasyonlarIçiin Rota Planlama", Uludağ University Journal of The Faculty of Engineering, 23(4), ss. 11-26.

Eliker, K., Zhang, G., Grouni, S., \& Zhang, W., 2018, “An Optimization Problem for Quadcopter Reference Flight Trajectory Generation", Journal of Advanced Transportation, 2018, ss. 1-15.

Hu, D., Wang, H., \& Zhu, Q., 2016, “Emergency Control of AR Drone Quadrotor UAV Suffering a Total Loss of One Rotor", IEEE Photonics Journal, 8(2), ss. 1-8.

Lin, C. E., \& Supsukbaworn, T., 2017, “Development of Dual Power Multirotor System”, International Journal of Aerospace Engineering, 2017, ss. 1-19.

López-Estrada, F. R., Ponsart, J.-C., Theilliol, D., Zhang, Y., \& Astorga-Zaragoza, C.-M., 2016, “LPV ModelBased Tracking Control and Robust Sensor Fault Diagnosis for a Quadrotor UAV", Journal of Intelligent \& Robotic Systems, 84(1-4), ss. 163-177.

Moussid, M., Idalene, A., Sayouti, A., \& Medromi, H., 2015, “Autonomous HexaRotor Arial Dynamic Modeling and a Review of Control Algorithms", International Research Journal of Engineering and Technology (IRJET), ss. 1197-1204.

Mueller, M. W., \& D'Andrea, R., 2014, “Stability and control of a quadrocopter despite the complete loss of one, two, or three propellers", Proceedings - IEEE International Conference on Robotics and Automation, ss. 45-52.

Muliadi, J., \& Kusumoputro, B., 2018, "Neural Network Control System of UAV Altitude Dynamics and Its Comparison with the PID Control System", Journal of Advanced Transportation, 2018(D), ss. $1-18$.

Nguyen, N. P., \& Hong, S. K., 2018, “Fault-tolerant Control of Quadcopter UAVs Using Robust Adaptive Sliding Mode Approach", Energies, 12(1), ss. 1-15.

Niemiec, R., \& Gandhi, F., 2017, "Multirotor Controls, Trim, and Autonomous Flight Dynamics of Plusand Cross-Quadcopters", Journal of Aircraft, 54(5), ss. 1910-1920.

Russell, C., Jung, J., Willink, G., \& Glasner, B., 2016, “Wind Tunnel and Hover Performance Test Results for Multicopter UAS Vehicles", In Proceedings of the AHS International 72nd Annual Forum, ss. 3448-3467. 
Solovyev Viktor, V., Finaev Valery, I., Zargaryan Yuri, A., Shapovalov Igor, O., \& Beloglazov Denis, A., 2006, "Simuation of wind effect on quadrotor flight", ARPN Journal of Engineering and Applied Sciences, 10(4), ss. 1535-1538.

Yılmaz, H. M., Mutluoğlu, Ö., Ulvi, A., Yaman, A., \& Bilgilioğlu, S. S., 2018, “İnsansız Hava Aracı ile Ortofoto Üretimi ve Aksaray Üniversitesi Kampüsü Örneği", Geomatik, 3(2), ss. 129-136.

Zabunov, S., \& Mardirossian, G., 2018, "Innovative Dodecacopter Design - Bulgarian Knight", International Journal of Aviation, Aeronautics, and Aerospace, 5(4), ss. 1-16 